\title{
Clinical impact of omalizumab treatment in children with severe asthma. Report of a local experience
}

\author{
Verónica Giubergia, M.D. ${ }^{a}$, María J. Ramírez Farías, M.D. ${ }^{a}$, Verónica Pérez, M.D. ${ }^{a}$, \\ Nancy Crespi, B.S. ${ }^{a}$ and Claudio Castaños, M.D. ${ }^{a}$
}

\begin{abstract}
Omalizumab, an anti-IgE monoclonal antibody, is indicated for the treatment of severe asthma. A longitudinal (pre-/post-intervention), observational, analytical study was conducted to assess the clinical and functional course of patients with uncontrolled severe asthma, 16 weeks before and after treatment.

Asthma was controlled in 17 cases $(p=0.00001)$. Exacerbations were reduced by $48.5 \%(p=0.009)$ and severe crises, by $100 \%(p=0.001)$. Before omalizumab treatment, 16 patients $(94 \%)$ had exacerbations, whereas $10(59 \%)$ had them after treatment $(p=0.005)$. None of the patients was hospitalized $(p=0.007)$. The dose of inhaled corticosteroids was reduced by $20 \%$ (0.002); the number of patients using continuous oral corticosteroids $(p=0.01)$, salbutamol $(p=0.001)$, and oral corticosteroids $(p=0.003)$ also decreased. Pulmonary function was not affected. Two patients had mild adverse reactions.

Omalizumab achieved an adequate asthma control in patients with severe asthma.

Key words: asthma, child, omalizumab.
\end{abstract}

http:/ / dx.doi.org/10.5546/ aap.2019.eng.e115

To cite: Giubergia V, Ramírez Farías MJ, Pérez V, Crespi N, Castaños C. Clinical impact of omalizumab treatment in children with severe asthma. Report of a local experience. Arch Argent Pediatr 2019;117(2):e115-e120.

\section{GLOSSARY}

a. Department of Pulmonology of Hospital "Prof. Dr. Juan P. Garrahan," Autonomous City of Buenos Aires.

E-mail address:

Verónica Giubergia, M.D.: verogiubergia@gmail.com

Funding:

None.

Conflict of interest:

None.

Received: 2-2-2018

Accepted: 11-5-2018
SA: severe asthma.

LABA: long-acting beta ${ }_{2}$-agonists.

ICS: inhaled corticosteroids.

OCS: oral corticosteroids.

COCS: continuous oral corticosteroids.

FVC: forced vital capacity.

FEF 25/75\%: forced expiratory flow between $25 \%$ and $75 \%$ of the FVC.

GINA: Global Initiative for Asthma.

GLI: Global Lung Function Initiative.

IgE: immunoglobulin E.

mAb: monoclonal antibody.

PANAG: Health Care Program for Children with Severe Asthma (Programa de Atención de Niños con Asma Grave).
ACT: asthma control test.

ICU: intensive care unit.

$\mathrm{FEV}_{1}$ : forced expiratory volume in 1 second.

$\mathrm{FEV}_{1} / \mathrm{FVC}$ : forced expiratory volume in 1 second and forced vital capacity ratio.

\section{INTRODUCTION}

Asthma is the most common chronic disease in pediatrics, with a high prevalence and morbidity. ${ }^{1,2}$ In Latin America, half of asthma patients are not adequately controlled. ${ }^{3}$ In Argentina, asthma causes more than 400 deaths yearly $-10 \%$ in patients aged 5-39 years- and more than 15000 hospitalizations. ${ }^{4}$ This occurs in patients with severe asthma (SA) who, although they account for only $5-7 \%$ of all asthma patients, are a very vulnerable group..$^{5-7}$

Children with SA have severe exacerbations and frequent hospitalizations; they seek emergency care 15 times more and are hospitalized 20 times more than those with mild to moderate asthma. ${ }^{5,8}$ Usually, clinical control is achieved with very high doses of inhaled corticosteroid (ICS) in association with long-acting beta ${ }_{2}-$ agonists (LABA) and montelukast or continuous oral corticosteroids (COCS), at risk of adverse events. The Argentine Asthma Consensus and the Global Initiative for Asthma (GINA) have recommended new therapeutic strategies, such as monoclonal antibodies $(\mathrm{mAb})$, to control asthma and reduce ICS and COCS use. ${ }^{1,2}$

Omalizumab, the first $\mathrm{mAb}$ approved for uncontrolled SA (step 5 of treatment), blocks free circulating IgE and controls airway inflammation. ${ }^{1,2,9,10}$ Several clinical 
trials in adults, although fewer in children, have established that omalizumab reduces the number and severity of exacerbations and hospitalizations and improves the quality of life. ${ }^{11-14}$ Its effectiveness is determined as of 16 weeks of treatment. ${ }^{15,16}$

SA management may take up to $29 \%$ of a family income. ${ }^{17}$ Considering the high cost of $\mathrm{mAb}$, it is necessary to carefully assess their usefulness, especially in countries with limited financial resources like Argentina. This study was designed to assess the clinical and functional course of patients with uncontrolled SA under treatment with omalizumab.

\section{POPULATION AND METHODS}

This was a prospective, longitudinal (pre-/ post-intervention), observational, analytical study to analyze the usefulness of omalizumab treatment in patients with SA with follow-up under the Health Care Program for Children with Severe Asthma (Programa de Atención de Niños con Asma Grave, PANAG) of Hospital Garrahan. ${ }^{5}$

All cases with uncontrolled SA who received treatment between August 2012 (initiation of omalizumab implementation at the hospital) and December 2017 were included. Patients who missed their follow-up visits were excluded.

The extent of control, the number and severity of exacerbations, hospitalizations, salbutamol and OCS use for exacerbations, COCS use, pulmonary function, and ICS dose reduction (25-50\% every 3 months) were compared between 16 weeks before and 16 weeks after omalizumab treatment initiation. $^{2}$

To confirm the diagnosis and extent of control, patients were assessed in the PANAG for 6 months before omalizumab indication. Children from across Argentina attend the program every month or every two months. Their clinical course, the number and type of exacerbations, hospitalizations, medication use for the chronic condition and for exacerbations, and spirometry details are recorded. In case of an exacerbation, children attend the hospital's Department of Pulmonology or emergency department every day. They receive medication at no charge (fluticasone/ salmeterol $250 \mu \mathrm{g} / 25 \mu \mathrm{g}$, montelukast) and participate in powerful education activities for the promotion of adherence and an adequate inhalation technique. Omalizumab is provided by the patient's social insurance program or managed care organization or by the National Ministry of Health. ${ }^{5}$
All patients met the criteria for omalizumab indication: $\geq 6$ years old, allergic asthma ( $\operatorname{IgE}$ between 30 and $1500 \mathrm{IU} / \mathrm{mL}$, positive allergy skin test), step 5 of asthma treatment according to GINA ( $\geq 800 \mu \mathrm{g}$ budesonide or similar drug associated with LABA, anti-leukotrienes or COCS), and uncontrolled disease. ${ }^{1-3}$ The extent of control was assessed using the asthma control test (ACT) before starting treatment and at 16 weeks of omalizumab. Values $\leq 19$ indicated uncontrolled asthma. $^{18}$

Omalizumab was administered via subcutaneous injection with local anesthesia on the skin (lidocaine/prilocaine). This was done at the outpatient offices of the Department of Pulmonology by a trained nurse. Patients were monitored for 3 hours after the first 3 administrations and for 30 minutes after the rest. ${ }^{15}$ The dose and frequency of administration (monthly or biweekly) were determined based on weight and IgE levels (30-1500 IU/mL). ${ }^{7}$

Severe exacerbation was defined as OCS requirement for at least 3 days or hospitalization or visit to the emergency department; mild exacerbation was defined when the event lasted $\geq 2$ days without OCS or hospitalization requirement, even if the patient visited the emergency department. ${ }^{19}$

Pulmonary function was assessed using a Medgraphics spirometer (MGC Diagnostics). $\mathrm{FVC}, \mathrm{FEV}_{1}, \mathrm{FEV}_{1} / \mathrm{FVC}$ and FEF 25/75 \% were analyzed. All parameters were expressed in percentages. The theoretical values proposed by the Global Lung Function Initiative (GLI, 2012) were used. ${ }^{20}$

The objectives of this study were explained to patients and their parents or legal guardians, who gave their consent for participation. The Ethics Committee approved the study.

\section{STATISTICS}

Categorical outcome measures were described as absolute and relative frequencies; continuous outcome measures, as mean and confidence interval/standard deviation or median and interquartile range. Categorical outcome measures were compared using the $\chi^{2}$ test; continuous outcome measures, using Student's tests for paired data or Wilcoxon's test. $P$ values $\leq 0.05$ were considered significant. The Stata XIV software (Stata-Corp, College Station, TX) was used. 


\section{RESULTS}

Out of 73 patients followed-up in the PANAG due to problematic SA, 33 were diagnosed with SA. ${ }^{21}$ Of these, $17(51.5 \%)$ were treated with omalizumab. Omalizumab was not indicated in the remaining patients ( $\mathrm{n}: 16)$ because IgE levels were out of range (n: 5$)$ or they were younger than 6 years (n: 2$)$ or had controlled asthma with high doses of ICS (n: 9).

The characteristics of the population are presented in Table 1. All patients had been hospitalized due to asthma before follow-up in the PANAG; $10(58.8 \%)$ required admission to the ICU, and 7 of them $(70 \%)$, assisted mechanical ventilation.

Seven children received omalizumab every 2 weeks. The rest, every 4 weeks. Eight patients required 2 or more subcutaneous injections at each visit.

All patients had uncontrolled asthma at treatment initiation; $100 \%$ achieved an adequate control after receiving omalizumab $(p<0.001)$ (Figure 1).

The overall number of exacerbations was reduced by $48.5 \%$ (35 and 18 events before and after treatment, respectively, $p=0.009$ ), and the number of severe crises, by $100 \%$ (23 and 0 events before and after treatment, respectively, $p=0.001$ ).

Sixteen patients $(94 \%)$ had exacerbations before treatment, whereas 10 (59\%), after receiving omalizumab; the rate of reduction was $40 \%(p=0.005)$. The number of patients with severe crises reduced by $100 \%: 10 / 17$ patients before omalizumab, no patients after treatment $(p=0.0002)$. Likewise, the number of crises per patient reduced by $55 \%(p=0.002)$ (Table 2$)$.

No hospitalizations were reported after omalizumab treatment $(p=0.007)$. Similarly,

TABLE 1. General characteristics of children under treatment with omalizumab

\begin{tabular}{lc}
\hline Outcome measures & Patients (n: 17) \\
\hline Age (years old) & $11.5(8.2-16)^{*}$ \\
Male sex (n, \%) & $8(47)$ \\
Allergic rhinitis $(\mathrm{n}, \%)$ & $7(41.1)$ \\
Positive allergy skin test $(\mathrm{n}, \%)$ & $17(100)$ \\
Eosinophilia (eosinophils $\left./ \mathrm{mm}^{3}\right)$ & $602(222-870)^{*}$ \\
Serum IgE (IU/mL) & $421(186-1220)^{*}$ \\
IgE < 30 (n, \%) & $0(0)$ \\
IgE 30-500 (n, \%) & $9(52.9)$ \\
IgE $>500(\mathrm{n}, \%)$ & $8(47)$ \\
Obesity $(\mathrm{n}, \%)$ & $4(23.5)$ \\
Gastroesophageal reflux $(\mathrm{n}, \%)$ & $1(5.8)$ \\
\hline
\end{tabular}

${ }^{*}$ Median with interquartile range. salbutamol $(p=0.001)$ and OCS use $(p=0.002)$ were also reduced. The dose of ICS was reduced by $20 \%(207 \mu \mathrm{g}, p=0.002)$. Fewer patients required COCS $(p=0.01)$. Pulmonary function was not affected by treatment (Table 2).

Two patients had redness at the injection site; in one of them, it was associated with facial erythema. These events resolved with oral antihistamines.

\section{DISCUSSION}

This study assessed, for the first time, the effectiveness of omalizumab in a population of Argentine children diagnosed with SA.

The greatest impact of omalizumab has been demonstrated in terms of clinical control, exacerbations, and hospitalization. ${ }^{12-15,22-26}$ The main outcome of this series was achieving total asthma control as referred by patients, as per the ACT. Different clinical trials in children have demonstrated the effectiveness of this drug in relation to the rate of exacerbations, with a smaller effect on symptom control, especially in children aged 6-11 years. ${ }^{11-14}$ In this series, $60 \%$ of children were older than 11 years and, in all cases, asthma was adequately controlled.

FIGURE 1. Asthma control test before and after omalizumab treatment ( $n: 17)$

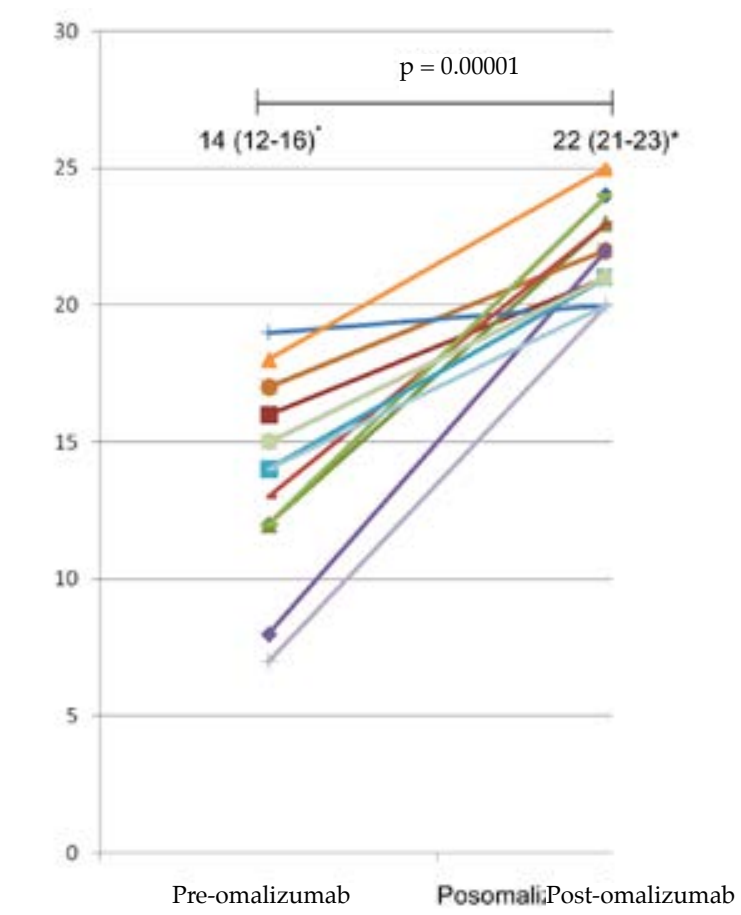

* Values are expressed as average and confidence interval $(95 \% \mathrm{CI})$. 
In relation to exacerbations, data from a recently published meta-analysis have shown a $65 \%$ reduction in the number of events. ${ }^{11}$ Likewise, other studies have observed a positive effect on exacerbations and hospitalizations in children after 1-2 years of treatment, with a $88.5 \%$ reduction in hospitalizations. ${ }^{22,23}$ In this series, exacerbations decreased by $48.5 \%$ and the rate of severe exacerbations, by $100 \%$. There were no hospitalizations or ICU admissions, which evidenced that this intervention was highly effective. These outcomes reinforce prior observations of a $43-50 \%$ reduction in exacerbations in children with moderate to severe asthma receiving omalizumab treatment. ${ }^{12,13}$ Consistent with other series, the effect on crisis frequency was observed early, in the first 4 months of treatment. ${ }^{24,25}$ Similar results were observed in the region. ${ }^{26}$

Another treatment benefit was its effect on OCS and ICS requirements. The lower use of OCS was, in general, an expected consequence of the significant reduction in the number of exacerbations, like the lower salbutamol requirement. The clinical relevance of the reduction in OCS use was noteworthy, given the morbidity associated with OCS use in pediatrics, especially when used continuously. In this series, like in others, omalizumab had a positive effect to reduce the number of patients receiving COCS; these were discontinued after 16 weeks in 4 out of 5 children and after 6 months of treatment in the remaining patient. ${ }^{22,25}$

The effects of omalizumab on the use of ICS have been studied. The extent of reduction in the dose of ICS varies depending on study design and patient severity. ${ }^{14,22-23}$ In this series, in spite of the brief treatment period, it was possible to reduce the dose of ICS by $20 \%$ in almost all patients. Similar results were reported after 1 year of treatment, which were more evident in patients with more severe asthma. ${ }^{14}$ However, other series failed to demonstrate this effect or showed only a reduction of less than $5 \% .12,26$

Pulmonary function may predict a loss of asthma control. It has been proposed that $\mathrm{FEV}_{1}<$ $60 \%$ may be an independent risk factor for future exacerbations. ${ }^{2}$ However, both in children and adults, a lack of association between symptoms and $\mathrm{FEV}_{1}$ has been demonstrated. Likewise,

TABLE 2. Progress of studied outcome measures before and after omalizumab treatment

\begin{tabular}{|c|c|c|c|}
\hline \multirow[t]{2}{*}{ Outcome measures } & \multicolumn{2}{|c|}{ Patients (n: 17) } & \multirow[t]{2}{*}{$p$-value } \\
\hline & Pre-omalizumab & Post-omalizumab & \\
\hline Patients with asthma attacks (n, \%) & $16(94)$ & $10(59)$ & 0.005 \\
\hline Patients with severe attacks (n, \%) & $10(59)$ & $0(0)$ & 0.0002 \\
\hline Number of exacerbations per patient & $2.2(1.1-3.3)^{*}$ & $1(0.6-1.4)^{*}$ & 0.002 \\
\hline Number of severe exacerbations per patient & $1.4(0.4-2.4)^{*}$ & 0 & 0.005 \\
\hline Hospitalized patients $(\mathrm{n}, \%)$ & $6(35 \%)$ & $0(0 \%)$ & 0.004 \\
\hline Number of hospitalizations per patient & $0.5(0.12-0.9)^{*}$ & 0 & 0.007 \\
\hline \multicolumn{4}{|l|}{ Treatment of asthma attacks } \\
\hline Days of oral corticosteroids & $12(5.5-18)^{*}$ & $4.5(2-7)^{*}$ & 0.03 \\
\hline Days of salbutamol & $27.4(9.8-45.1)^{*}$ & $9.3(1.8-16.7)^{*}$ & 0.002 \\
\hline \multicolumn{4}{|l|}{ Chronic treatment } \\
\hline Daily ICS doses CI ( $\mu \mathrm{g})$ & $1053.3(1002-1104)^{*}$ & $846.6(697-996)^{*}$ & 0.002 \\
\hline Patients using OCS $(\mathrm{n}, \%)$ & $5(29.4)$ & $1(6)$ & 0.01 \\
\hline \multicolumn{4}{|l|}{ Pulmonary function* $(\%)$} \\
\hline FVC & $106(98-114)$ & 101 (93-109) & 0.1 \\
\hline $\mathrm{FEV}_{1}$ & $95(84-105)$ & $90(80-99)$ & 0.1 \\
\hline $\mathrm{FEV}_{1} / \mathrm{FVC}$ & $80(73-88)$ & $80(70-86)$ & 0.2 \\
\hline MMFEF & $73(53-94)$ & $73(51-95)$ & 0.4 \\
\hline
\end{tabular}

* Values are expressed as average and confidence interval (95\% CI).

ICS: inhaled corticosteroids. OCS: oral corticosteroids.

FVC: forced vital capacity.

FEV1: forced expiratory volume in 1 second.

FEV1/FVC: forced expiratory volume in 1 second and forced vital capacity ratio.

MMFEF: mean and maximal forced expiratory flow. 
there is a small correlation between pulmonary function and asthma severity. For this reason, a spirometry is not a parameter usually taken into consideration to assess the effectiveness of omalizumab.

Some clinical trials have reported a modest, but not clinically relevant, improvement in $\mathrm{FEV}_{1}$ after omalizumab treatment. ${ }^{22,23}$ In this cohort of patients with SA, as in others, spirometry parameters were normal or almost normal before omalizumab treatment, although asthma was not adequately controlled. ${ }^{21,26,27}$ Pulmonary function was not significantly affected by treatment.

More than $85 \%$ of children with SA are atopic, as defined by the high levels of serum IgE and positive skin tests to common aeroallergens. ${ }^{28}$ Omalizumab significantly reduces the levels of free IgE and the high and low affinity IgE receptors expressed on basophils, mast cells and dendritic cells, thus preventing inflammatory mediator release. ${ }^{29}$ Effectiveness is determined at 16 weeks based on quality of life questionnaires and exacerbations. IgE levels are not taken into account because free IgE levels cannot be assessed routinely yet. ${ }^{15}$ The effectiveness reported in real life situation studies has been over $80 \%$, which is higher than that observed in clinical trials. ${ }^{22,23}$ As mentioned above, in this series, omalizumab was very effective considering that it controlled asthma in all cases and exacerbations decreased significantly. It is worth noting that the assessment of effectiveness at 16 weeks of treatment is consistent with its mechanism of action based on the reduction of free serum $\operatorname{IgE}$ to very low or undetectable levels, with a $97 \%$ reduction in the expression of the high affinity $\operatorname{IgE}$ receptor on basophils at 90 days of treatment. ${ }^{15}$ Similarly, effectiveness parameters reach a plateau as of this moment, although effects persist after 5 years of treatment. ${ }^{30}$

The safety profile for omalizumab in children has been extensively assessed. ${ }^{11,22}$ In our series, no severe adverse events were recorded during the follow-up period. Pain and erythema at the injection site were the most common adverse events; no cases of anaphylaxis were observed, which confirmed its high safety profile.

Although patients with SA are a small part of the asthma population, they account for more than $50 \%$ of asthma-related costs. The impact on health care resources has been clearly described. ${ }^{17,31}$ Although cost reduction was not an objective of this study, in all cases, the use of the health system was reduced, especially in terms of visits to the emergency department and hospitalizations after treatment.

Some methodological observations should be made. An advantage of this study is that data were collected in a clinical setting without interventions; therefore, results reflect the progress of patients that were not selected and treated in accordance with national and international asthma consensuses. Data were collected from the PANAG's monthly or bimonthly records with a standardized visit follow-up, which warranted the quality of assessed outcome measures. Although it cannot be ruled out that the observed improvement is partially related to the subcutaneous route compared to ICS, the population was made up of children with uncontrolled asthma, followed for many years in the PANAG, which included routine monitoring of treatment adherence. ${ }^{5}$

Although the prevalence of SA is low, morbidity is very high due to its frequent severe crises. In this group of children, omalizumab treatment $w$ as effective because it reduced exacerbations and managed to control asthma in children who did not achieve SA control with traditional treatment options, which provided additional information to that published in other populations.

\section{REFERENCES}

1. Comité Nacional de Neumonología, Comité Nacional de Alergia, Comité Nacional de Medicina Interna, Comité Nacional de Familia y Salud Mental. Guía de diagnóstico y tratamiento: asma bronquial en niños $\geq 6$ años. Actualización de 2016. Resumen ejecutivo. Arch Argent Pediatr. 2016; 114(6):595-6.

2. Global Initiative for Asthma. Global Strategy for Asthma ManagementandPrevention. 2018. [Accessed on: November $\left.9^{\text {th }}, 2018\right]$. Available at: https: / / ginasthma.org / 2018-ginareport-global-strategy-for-asthma-management-andprevention/.

3. Neffen H, Vallejo-Perez E, Chahuan M, Giugno E, et al. Uncontrolled Asthma in Specialized Centers in Latin America: Findings from the Asthma Control in Latin America (ASLA) Study. J Allergy Clin Immunol. 2017; 139(2) Suppl:AB206.

4. Argentina. Ministerio de Salud. Secretaría de Políticas, Regulación e Institutos. Dirección de Estadísticas e Información de Salud. Estadísticas Vitales. Información básica - año 2014. 2016;5(58). [Accessed on: November $9^{\text {th }}$, 2018]. Available at: www.deis.msal.gov.ar/wp-content/ uploads / 2016/01/Serie5Nro58.pdf.

5. Giubergia V, Fridman N, González Pena H. Evaluación del impacto de un programa de atención de niños con asma grave. Arch Argent Pediatr. 2012; 110(5):382-7.

6. Bush A, Saglani S, Fleming L. Severe asthma: looking beyond the amount of medication. Lancet Respir Med. 2017; 5(11):844-6.

7. Neffen H, Vidaurreta S, Balanzat A, De Gennaro MS, et al. Asma de difícil control en niños y adolescentes. Estrategias diagnóstico-terapéuticas. Medicina (B Aires). 2012; 72(5):403-13. 
8. Hedlin G, Bush A, Lødrup Carlsen K, Wennergren G, et al. Problematic severe asthma in children, not one problem but many: a GA2LEN initiative. Eur Respir J. 2010;36(1):196201.

9. Licari A, Castagnoli R, Panfili E, Marseglia A, et al. Update on Anti-IgE Therapy in Pediatric Respiratory Diseases. Curr Respir Med Rev. 2017; 13(1):22-9.

10. Djukanović R, Wilson SJ, Kraft M, Jarjour NN, et al. Effects of treatment with anti-immunoglobulin E antibody omalizumab on airway inflammation in allergic asthma. Am J Respir Crit Care Med. 2004; 170(6):583-93.

11. Rodrigo GJ, Neffen H. Systematic review on the use of omalizumab for the treatment of asthmatic children and adolescents. Pediatr Allergy Immunol. 2015; 26(6):551-6.

12. Lanier B, Bridges T, Kulus M, Taylor AF, et al. Omalizumab for the treatment of exacerbations in children with inadequately controlled allergic (IgE-mediated) asthma. J Allergy Clin Immunol. 2009; 124(6):1210-6.

13. Kulus M, Hébert J, Garcia E, Fowler Taylor A, et al. Omalizumabin children with inadequately controlled severe allergic (IgE mediated) asthma. Curr Med Res Opin. 2010; 26(6):1285-93.

14. Busse WW, Morgan WJ, Gergen PJ, Mitchell HE, et al. Randomized trial of omalizumab (anti-IgE) for asthma in inner-city children. N Engl J Med. 2011; 364(11):1005-15.

15. Bousquet J, Siergiejko Z, Swiebocka E, Humbert M, et al. Persistency of response to omalizumab therapy in severe allergic (IgE-mediated) asthma. Allergy. 2011; 66(5):671-8.

16. Holgate ST. How to evaluate a patient's response to antiIgE. Eur Respir Rev. 2007; 16:78-84.

17. De Andrade WC, Lasmar LM, Ricci C de A, Camargos PA, et al. Phenotypes of severe asthma among children and adolescents in Brazil: a prospective study. BMC Pulm Med. 2015; 15:36.

18. Rodrigo GJ, Arcos JP, Nannini LJ, Neffen H, et al. Reliability and factor analysis of the Spanish version of the asthma control test. Ann Allergy Asthma Immunol. 2008;100(1):17-22.

19. Reddel H, Taylor R, Bateman ED, Boulet LP et al. An Official American Thoracic Society / European Respiratory Society Statement: Asthma Control and Exacerbations: standardizing andpoints for clinical asthma trials and clinical practice. Am J Respir Crit Care Med. 2009; 180(1): 59-99.
20. Quanjer PH, Stanojevic S, Cole TJ, Baur X, et al. Multiethnic reference values for spirometry for the 3-95-yr age range: the global lung function 2012 equations. Eur Respir J. 2012; 40(6):1324-43.

21. Giubergia V, Ramírez Farías MJ, Pérez V, González A, et al. Asma grave en pediatría: resultados de la implementación de un programa especial de atención. Arch Argent Pediatr. 2018; 116(2):105-11.

22. Normansell R, Walker S, Milan SJ, Walters E, et al. Omalizumab for asthma in adults and children. Cochrane Database Syst Rev. 2014; (1):CD003559.

23. Deschildre A, Marguet $\mathrm{CH}$, Langlois C, Pin I, et al. Reallife long-term omalizumab therapy in children with severe allergic asthma. Eur Respir J. 2015; 46(3):856-9.

24. Milgrom H, Berger W, Nayak A, Gupta N, et al. Treatment of childhood asthma with anti-immunoglobulin Eantibody (omalizumab). Pediatrics. 2001; 108(2):E36.

25. Brodlie M, McKean MC, Moss S, Spencer DA. The oral corticosteroid-sparing effect of omalizumab in children with severe asthma. Arch Dis Child. 2012; 97(7):604-9.

26. Pitrez PM, de Souza RG, Roncada C, Heinzmann-Filho JP, et al. Impact of omalizumab in children from a middleincome country with severe therapy-resistant asthma: A real-life study. Pediatr Pulmonol. 2017; 52(11):1408-13.

27. Lødrup Carlsen KC, Mowinckel P, Hovland V, Håland G, et al. Lung function trajectories from birth through puberty reflect asthma phenotypes with allergic comorbidity. I Allergy Clin Immunol. 2014; 134(4):917-23.e7.

28. Martin Alonso A, Saglani S. Mechanisms Mediating Pediatric Severe Asthma and Potential Novel Therapies. Front Pediatr. 2017; 5:154.

29. Assayag M, Moshel S, Kohan M, Berkman N. The effect of omalizumab treatment on the low affinity immunoglobulin E receptor (CD23/fc epsilon RII) in patients with severe allergic asthma. Allergy Asthma Proc. 2018; 39(1):36-42.

30. Chipps BE, Lanier B, Milgrom H, Deschildre A, et al. Omalizumab in children with uncontrolled allergic asthma: Review of clinical trial and real-world experience. J Allergy Clin Immunol. 2017; 139(5):1431-44.

31. SzeflerSJ, Zeiger RS, Haselkorn T, MinkDR, et al.Economic burden of impairment in children with severe or difficult-totreat asthma. Ann Allergy Asthma Immunol. 2011;107(2):1109.e1. 